\title{
On the behavior of the numerical abscissa in the triangular matrices case
}

\author{
ABDELKADER FRAKIS and ABDERRAHMANE SMAIL
}

\section{ABSTRACT.}

L. Trefethen gave a conjecture concerning a phenomenon linked to the initial transient and asymptotic behavior of $\|\exp (t A)\|$ as a function of $t$ at time $t=0,(t \rightarrow \infty$ is a familiar limit). Motivated by this interesting phenomenon, we propose an answer for it in this particular case and in a general one as well. Also some results concerning particular quantities which are important in the study of time-dependent dynamical systems are given.

Department of MATHEMATICS AND COMPUTER SCIENCE

UNIVERSITY OF MASCARA

32 Chergui AeK , 29200, Tighennif, Algeria

E-mail address: aekfrakis@yahoo.fr

DEPARTMENT OF MATHEMATICS

UNIVERSITY OF ORAN

E-mail address: smaine58@yahoo.fr 